\title{
O FEMININO, A LITERATURA E A SEXUAÇÃO
}

\author{
Rahel Patrasso* \\ Walkiria Helena Grant**
}

\section{RESUMO}

Propomos, a partir da questão enunciada por Freud e retomada por Lacan, "o que quer uma mulher?”, abordar algumas das diferentes maneiras pelas quais, no século XIX e no cenário contemporâneo, se tentou responder à questão do feminino. Para tanto, apresentamos um recorte sobre o cenário das produções discursivas do século XIX, século do advento da psicanálise, e sobre o cenário contemporâneo, a partir de três eixos que consideramos fundamentais: o tempo, o capital e a imagem.

Palavras-chave: feminino, literatura, sexuação, psicanálise, contemporaneidade

\section{AbSTRACT}

KEYWORDS: FEMININE, LITERATURE, SEXUALITY, PSYCHOANALYSIS, CONTEMPORARINESS

This paper approaches different attempts to answer to the question raised by Freud and Lacan: "what does a woman want?". In this article we present an overview of the discursive production of the century XIX, century of the advent of psychoanalysis, and of the contemporary scene, from the perspective of three factors: capital, time and image.

Keywords: feminine, sexuality, literature, psychoanalysis, contemporariness.

* Especialista em Psicologia Clínica pela Universidade de São Paulo.

** Professora Doutora Aposentada do Instituto de Psicologia da Universidade de São Paulo (IPUSP); Psicanalista Membro da Associação Campinense de Psicanálise (ACP). 
Que antes renuncie a isso, portanto, quem não conseguir alcançar em seu horizonte a subjetividade de sua época. Pois como poderia fazer de seu ser o eixo de tantas vidas quem nada soubesse da dialética que o compromete com essas vidas num movimento simbólico. Que ele conheça bem a espiral a que o arrasta sua época na obra continua de Babel, e conheça sua função de intérprete na discórdia das línguas. Jacques Lacan (1953/1998: 322)

Em 8 de Julho de 1882, de acordo com Jones (1989), Sigmund Freud escreve a sua noiva Martha Bernays - futura senhora Freud:

Acho que existe uma inimizade geral entre artistas e aqueles que se dedicam aos detalhes do trabalho científico. Sabemos que aqueles possuem em sua arte uma chave-mestra para abrir com facilidade os coraçōes femininos, ao passo que nós permanecemos desamparados perante o estranho desenho da fechadura e temos primeiro que nos atormentar para descobrir uma chave apropriada (Jones, 1989: 121-22).

Mais de trinta anos depois, Freud escreve uma carta a outra mulher, Marie Bonaparte: "A grande indagação que ficou sem resposta, à qual eu mesmo não soube responder, apesar de meus trinta anos de estudo da alma feminina, é a seguinte: Was will das Weib? - O que quer a mulher?" (Rodrigué, 1995: 128).

Lacan retomará a interrogação freudiana modificando-a: $o$ que quer uma mulher? A reformulação desta questão permite, segundo André (1998), questionar se "existiria um voto cujo objeto seria de uma fixidez inabalável para toda mulher" (André, 1998: 17). Existiria uma natureza "feminina", uma "verdade" sobre a mulher, cuja chave-mestra Freud não teria encontrado a fim de decifrá-la, ou a mulher só pode ser escutada uma a uma, como nos propõe a interrogação lacaniana?

O que, hoje, poderíamos nós, psicanalistas, dizer sobre a verdade? Sobre a verdade de um saber, sobre a verdade da mulher? Freud já havia demonstrado, em seus estudos sobre o lapso, que é no erro, no equívoco, no ato falho que se confessa a "verdade" em ato. André (1998) nos diz:

O saber psicanalítico não funciona, em posição de verdade, a não ser na medida em que opera como saber furado, afetado por uma falha central. [...] Lacan nos convida a compreender que esta falha não é da ordem de uma imperfeição que os progressos da pesquisa permitiriam preencher, mas sim que ela constitui a chave para a própria estrutura do saber (André, 1998: 10; grifo nosso). 
Assim, mulher e verdade compartilham da falta, da falha estrutural, condição para que operem em sua especificidade e produzam laços sociais. Desta forma, falar da mulher, no campo freudo-lacaniano, não é referir-se ao masculino ou ao feminino como gênero, mas é apontar uma posição psíquica em que a castração ocupa um lugar importante. Esta posição psíquica marcada pela castração pode ser escutada pelo analista, médico, amante, etc, a partir de um discurso marcado por um mal-estar e, ao mesmo tempo, convocando aquele que o escuta a doar a palavra, o dinheiro, etc, que lhe falta.

Lacan (1972-73/1985) nos diz: "A mulher não existe". Percebam que em A mulher o A é barrado, isto é, o que não existe é uma "A mulher... toda", não existe um conjunto fechado de mulheres. Ocorre que a sexuação é uma resultante da função fálica: operador fundamental que nos humaniza a partir do momento em que nos mergulha no mundo da linguagem, em que nos abre a possibilidade de estabelecermos laços sociais. Ocorre que a mulher, diferentemente do homem, é não toda submetida à função da castração, é não toda marcada pelo gozo fálico. Dito de outro modo: a mulher é um ser de linguagem, pois a função fálica operou; de outro lado, pelo fato de a mulher ser não toda submetida à operação da castração, resta um real impossível de ser capturado pelas palavras, resta um Outro gozo marcando a especificidade de cada mulher - sua maneira de ser pura exceção. Como há exceção, não é possível formar um conjunto fechado de "A mulher". Temos, portanto, que as mulheres só existem uma a uma...

Esta proposição lacaniana ajuda-nos, portanto, a responder nossa primeira indagação, que dizia respeito ao querer da mulher, e este é da ordem da singularidade. Desta maneira temos que, masculino ou feminino não dizem respeito ao gênero biológico - macho ou fêmea -, mas a uma posição psíquica marcada por um gozo: fálico ou não todo fálico.

Dizer da posição psíquica feminina, em termos psicanalíticos, implica abordar a questão da sexuação pelo viés da linguagem e do gozo. Desta forma, entendemos que uma posição subjetiva feminina diz respeito a estar não toda submetida à égide do falo. Esta maneira difere dos conceitos, ou das representações sobre a feminilidade que, por sua vez, correspondem a uma "invenção" cultural, produçôes discursivas ou imaginárias que tentam dar contorno a este vazio próprio e estrutural da posição feminina, assumindo diferentes roupagens ao longo do tempo e produzindo possíveis deslocamentos e enodamentos.

Desta forma, propomos abordar algumas das diferentes maneiras com as quais, ao longo do tempo, tentaram responder à questão do feminino, a partir de um recorte sobre o cenário do século XIX e o cenário contemporâneo. Nestes diferentes cenários, privilegiaremos três aspectos fundamentais: o capital, o tem- 
po e a imagem, pois supomos que tais variáveis podem nos ajudar a desvelar a tessitura da produção discursiva sobre o feminino.

Por hora, voltemos às proposições lacanianas de modo a tornar mais claro o que insistimos em chamar de posição psíquica feminina, diferenciando-a de uma produção imaginária e ou discursiva cultural.

Uma vez que a mulher é não-toda submetida à castração, não há um significante que represente o feminino enquanto tal. Uma das maneiras de abordarmos a formulação lacaniana de que a "mulher não existe", de acordo com Grant (1998), é supor que “a feminilidade é da ordem do uso de uma máscara, máscara de aparência feminina” (Grant, 1998: 255). Supomos que, por efeito de estrutura, este lugar do feminino permanece vazio e precisa ser recoberto por semblantes, por máscaras de aparência feminina, pois, mais além da máscara, resta o nada. Estas máscaras são tecidas através do discurso que atravessa o ser e permite a constituição de um sujeito.

Concordamos com Kehl (1998) no pressuposto de que uma obra literária pode constituir-se como dispositivo analítico, na medida em que joga luz nos aspectos emergentes que perfazem as produções discursivas e o campo imaginário de uma determinada época, à medida que permite revelar a urdidura da trama discursiva sobre a qual cada mulher se engaja para constituir-se sujeito.

Para tratar destes diferentes cenários, escolhemos dois trabalhos literários: tomamos como ponto de partida Madame Bovary de Gustave Flaubert, publicado em 1856 (1971) em capítulos, na Revue de Paris, e como ponto de chegada o romance contemporâneo Aritmética, de Fernanda Young, publicado em 2004.

Dentre os vários fatores que permitiriam revelar a urdidura de uma produção discursiva e que tomam o feminino como uma variável histórica e cultural, destacamos as três vertentes fundamentais já mencionadas a serem consideradas na nossa discussão: o tempo, o capital e a imagem. Vamos, agora, nos ater a estes fatores e suas vicissitudes, sob um recorte do século XIX e outro do cenário contemporâneo, a partir das personagens: "Ema” Bovary, de Madame Bovary e, "Elisa", de Aritmética.

\section{O TEMPO}

A passagem da Idade Média para o Renascimento marca, do ponto de vista histórico, a Modernidade. Na Renascença surge o humanismo moderno. O homem, recém-saído do "período das trevas", é relançado no mundo sob as luzes da ciência. Assim, tentará organizar-se diante da dúvida e da aventura do devir. Uma vez que as leis que governam o mundo e seus fenômenos deixaram de ser divinas, 
sendo agora entendidas como "naturais", caberá ao homem desvendar os seus mistérios. Dentre as diversas conseqüências deste descentramento, destacamos a perda dos referenciais absolutos e o surgimento das idéias de individualidade e privacidade. Em oposição à mobilidade e ao descentramento originado pela modernidade, no século XIX constitui-se a família nuclear moderna como lugar de intimidade e privacidade: "um lugar sagrado, cuja harmonia e tranqüilidade estariam a cargo daquela que cada um escolheu como esposa” (Kehl, 1998: 52).

Este ideário da mulher coroada como "a rainha do lar" é exemplarmente descrito pelo filósofo Jean-Jacques Rousseau, em Emílio, ou da educação, publicado originalmente como Émile em 1782 (2004). Este ideal, não foi sem conseqüências para as mulheres. A literatura do século XIX experimentou uma proliferação de títulos escritos para o público feminino. Diz Kehl (1998), sobre este tipo de literatura: "os códigos burgueses, de si e do lar, compuseram o imaginário feminino sobre o casamento, moldando as expectativas românticas do amor-paixão pelo lado da literatura..." (Kehl, 1998: 108). As mulheres tão bem educadas como Sofia de Rousseau, depositárias do bem-estar familiar, deveriam cumprir o papel de estofo ante o desamparo experimentado diante da perda de referências absolutas e da corrida desenfreada do capital, característica da modernidade.

Ema, personagem do texto de Gustave Flaubert (1856/1971), apresentada formalmente como "Madame Bovary", respondendo aos apelos de seu tempo, desempenhava o papel de esposa séria, devotada, recatada e preocupada com o bem-estar da família e com a salvação de sua alma. Porém este ideal romântico, insuflado pela própria literatura do século XIX de que Ema é assídua leitora e personagem, insurgia-se contra a tempestade que, apoiada pelas idéias liberais iluministas de autonomia e liberdade, habitava sua alma.

Qual seria a possibilidade para Ema de encontrar esta via que a levaria da vida pacata e modesta da propriedade rural de seu pai para a sonhada, tumultuada e glamourosa vida de Paris, senão nos braços de um homem? Assim nos diz Ema:

Um homem não devia, ao contrário, primar em múltiplas atividades, saber iniciar uma mulher nos embates da paixão, nos requintes da vida, enfim, em todos os seus mistérios? Mas aquele não ensinava, nada sabia, nada desejava. Supunha-a feliz; e ela não lhe podia perdoar aquela tranqüilidade tão bem assente, aquela gravidade serena, nem a própria felicidade que ele lhe dava (Flaubert, 1856/1971: 37).

Parece-nos que este cenário acerca de Madame Bovary evidencia a condição das mulheres no século XIX. De um lado, a consolidação da burguesia na Europa, 
de outro, os ideais morais que cercaram as mulheres através do discurso asséptico da medicina, da filosofia e da moral religiosa. Entre estes dois extremos há um abismo, e, na tentativa de transpô-lo, assistimos à febre, ou melhor, aos sintomas que se alastraram, pelo século XIX, entre as mulheres, nosologicamente catalogados como histeria. Tal fenômeno parece apontar para o que anos mais tarde, aproximadamente meia década após a publicação de Madame Bovary, Freud (1908/ 1996) enunciará em "Moral sexual civilizada e a doença nervosa".

Neste texto, encontramos Freud dizendo que, para a mulher do século XIX, ou seja, de sua época: "resta-lhe a escolha entre o desejo insatisfeito, a infidelidade ou uma neurose" (Freud, 1908/1996: 182). Neste contexto, Ema parece-nos uma personagem exemplar de seu tempo, pois não havia podido em vida trilhar um outro destino para além da "paixão" que conheceu no convento onde foi educada. Lá, também conheceu nos livros o amor burguês, criado pela literatura do século XIX que inventou Ema, e da qual ela é leitora e protagonista. Em uma agonizante busca sobre "o que quer uma mulher?", Madame Bovary se "entrega" a Deus, Carlos, Léon e Rodolfo a partir da única posição que pôde ocupar: a de "objeto de desejo", ou seja, a posição em que a mulher, encarnando a posição feminina, se inscreve no par sexual. Assumindo, prioritariamente, esta posição, a de parceira do desejo masculino, Ema deixa em segundo plano a questão de seu próprio desejo, ou delega esta questão aos homens que serão seus tributários, como podemos acompanhar: "Um homem não devia, ao contrário, primar em múltiplas atividades, saber iniciar uma mulher nos embates da paixão, nos requintes da vida, enfim em todos os seus mistérios?" (Flaubert, 1856/1971: 37).

Ema não havia podido, em vida, trilhar um outro destino para além de "ser objeto de desejo". Julgando não poder decidir sobre seu destino, pode apenas decidir sobre sua morte apoteótica e, morrendo, escreve as últimas linhas de sua "Paixão": "Assim jaz Ema, morta de amor". Destacamos que, no caminho trilhado por Madame Bovary para que pudesse aceder ao seu nome próprio, Ema, e para que, neste processo, tivesse seu destino em suas mãos, a morte foi a escolha possível!

Tal cenário aponta para um campo muito estreito de "escolha", bem representado por nossa emblemática Ema. Neste contexto, pode-se, então, observar a dificuldade das mulheres para tecer discursos, a partir das representaçōes do feminino no século XIX, que pudessem apontar para outras saídas mais satisfatórias. Dito de outro modo, não eram poucas as dificuldades que, no século XIX, cada mulher, uma a uma, encontrava ao tentar fazer furo numa dada produção discursiva em que estava mergulhada e, assim, a partir de sua resposta singular, poder ampliar sua perspectiva narrativa. 
Num salto temporal para a contemporaneidade, trazemos Elisa, personagem de Fernanda Young (2004) em Aritmética que, por sua vez, enuncia que o gozo fálico parece cada vez mais acessível às mulheres. No que diz respeito ao gozo fálico, uma mulher não pode se fazer reconhecer, como tal, pelo que possui ou pelo que tem, e Elisa nos parece ser bastante ilustrativa disso, já que pode abandonar sua pobre infância e tornar-se uma jornalista renomada, entrando assim, em suas próprias palavras, no "mundo dos incríveis" (Young, 2004: 50).

Em Aritmética, para além das posses materiais, a chamada "liberação das mulheres", proporcionada em parte pelos ideais capitalistas, pela entrada no mercado de trabalho, retirou o homem do lugar de único representante e depositário do desejo feminino. As mulheres hoje não se dedicam exclusivamente a "arranjar um bom partido". Dedicam-se, entre muitas coisas, à carreira, a adquirir estabilidade financeira. Como nos diz Young (2004), a contemporaneidade diz respeito à:

hora do grande show da mulher moderna, e Elisa não decepcionou a platéia. [...] Centrífuga multiuso: mulher, mãe, cidadã, esposa, trabalhadora, formadora de opinião. A generala das forças familiares, com seus batalhões de babás, cozinheiras, faxineiras, motoristas, personal trainners, terapeutas, cabeleireiros, médicos. À noite, ainda tendo que reconstruir toda sua sexualidade... Para poder, enfim, batalhar por um orgasmo (Young, 2004: 164).

Elisa, porém, mesmo muito atarefada: "Sabia precisamente o homem que tinha ao lado. Ou os homens, incluindo Rigel. Era o tempo que gastava com isso, saber precisamente dos homens, que ela, às vezes, achava sem sentido. Já tinha marido, amante, poesia, sexo. O que ela queria afinal de contas? Ter tudo? Todos?" (Young, 2004: 69-70).

Sabemos que hoje é permitido às mulheres que escolham se querem, ou não, se casar, ter filhos, ter um parceiro fixo, ou zappear por diversos parceiros. De acordo com Pelbart (1993), vivemos o ideal do:

tempo zero e da distância zero. [...] As tecnologias do pós-guerra criaram um novo veículo, estático: a televisão. De propagação instantânea e indiferente à geografia, o áudio-visual inaugurou um novo regime de temporalidade: a instantaneidade. $\mathrm{O}$ instante sem duração, uma espécie de tempo presente, sem espessura. Em geral, temos muita pressa. Não temos nem paciência para sustentar este ponto, o ponto do surgimento de tempo, pois somos amantes das formas, da ordem dos projetos, do futuro já embutido no presente (Pelbart, 1993: 32-3). 
Podemos supor, de acordo com a afirmação de Pelbart (1993), que se a literatura no século XIX forneceu o modelo das parcerias amorosas, em que o tempo do casamento era marcado por um "toda a vida", as novas tecnologias inauguraram um novo regime que afeta a organização da sociedade como um todo e, também, estabelece um novo parâmetro para a conjugalidade.

O que ela, Elisa, queria afinal de contas? "Ter tudo? Ter todos?”. É demasiado arriscado e um tanto quanto "selvagem" tratar da insatisfação de Elisa atribuindo-lhe o diagnóstico de histeria. Sobre a histeria e a insatisfação muito já se disse. Preferimos apontar o caráter da insatisfação sob o signo do mais gozar, que nos parece tão característico da contemporaneidade. Queremos sempre mais e mais, instantaneamente, já que não temos tempo a perder. Fastfood, assistir a todos os canais da televisão a cabo ao mesmo tempo, zappear, afinal um só canal não é suficiente para nos deixar informados e entretidos. Ainda assim, ficamos insatisfeitos, nostálgicos do tempo em que a comida era feita em panela de ferro, no fogão a lenha. Do tempo em que não havia pressa, do romantismo que era esperar, por um mês, a carta de alguém querido e distante. Mas temos pressa de viver tudo ao mesmo tempo. Precisamos comprar a tecnologia mais recente, apesar de, às vezes, a rede ficar congestionada e um e-mail demorar intermináveis dez minutos para chegar, e nos fazer perder tempo, mais e mais. Mais ainda...

\section{O CAPITAL}

O capitalismo, paradigma econômico da modernidade, figura como modo de produção dominante nos países da Europa. A aventura do sujeito moderno, a de fazer si mesmo - "self made men" - do ponto de vista econômico, produz a possibilidade para a classe emergente, a burguesia, de fazer-se sujeito do próprio destino, à medida que o capital produz mobilidade social. Por outro lado, tal "liberdade" traz consigo o sofrimento próprio da modernidade, o sentimento de desamparo e de perda de claras referências, assim como de responsabilidade pelo destino pessoal.

$\mathrm{Na}$ modernidade, a burguesia encarna particulares ideários econômicos e culturais. Destes, nossa Ema é representante, por exemplo, do endividar-se para ter acesso a todos os bens materiais, como nos diz Flaubert (1856/1971: 222223): "todas as coisas que lhe tinham suavizado a amargura de vida". $\mathrm{Na}$ contemporaneidade, segundo Anderson (1999):

À medida que foi revolvida uma ordem industrial mais antiga, as tradicionais formaçôes de classe enfraqueceram-se, enquanto as identidades segmentadas, 
grupos localizados, tipicamente baseados em diferenças étnicas ou sexuais, multiplicaram-se. Em escala universal, na era pós-moderna, a arena decisiva - nenhuma estrutura de classe comparada à do capitalismo anterior, cristalizou-se ainda [...] tais condições, ainda são, de uma certa indefinição vertical (Anderson, 1999: 74-75).

Tal fenômeno tem uma repercussão que a nós interessa diretamente; de acordo com Anderson (1999: 76), um "significativo número de grupos até então excluídos - mulheres, imigrantes, minorias étnicas e outras - ganham acesso às formas pós-modernas, ampliando consideravelmente a base da produção artística”.

Neste cenário, as mulheres gradualmente passaram a tornar públicas suas intimidades, idéias, desejos e devaneios, que antes eram escritos, quase que secretamente, em seus diários. Aliás, esse tornar público, encurtar cada vez mais a fronteira entre o público e o privado, que foi inaugurado na modernidade, está no ditame do "manual da mulher pós-moderna". Mas esta questão será tratada no próximo item, que versa sobre a imagem.

Ainda no que diz respeito à mulher e à literatura, Coelho (1989), em seu texto "Tendências atuais da literatura feminina no Brasil" (1989), nos diz:

Há, na literatura feminina atual, algo mais, algo essencial dentro das transformaçôes em processo no ser humano e na sociedade, e que podemos definir como a busca da Nova mulher. Ou, em outras palavras, a busca do feminino autêntico, pressentido para além dos destroços da "imagem tradicional da mulher", patente na crise em processo de nossos tempos (Coelho, 1989: 4).

Young (2004), em seu texto, parece confirmar o que Coelho (1989) intitula como a "busca da Nova mulher", definindo-a: "Elisa [...] quer ser vanguarda de uma nova geração de mulheres. Que não precisa de homens, ou que não precisará pelos motivos que hoje precisa. Mulheres serão menos chatas, menos carentes, menos desesperadas. Criarão filhas mais fortes e filhos mais frágeis" (Young, 2004: 332-3).

Tal como nos dizia Anderson (1999), não é apenas em relação às artes que a inserção dos grupos excluídos nos meios de produção, dentre as quais figuravam as mulheres, fez efeito. A chamada "liberação das mulheres", proporcionada, em parte, pelos ideais capitalistas, pela entrada no mercado de trabalho, permitiu este termo em moda, a saber, a inclusão cada vez maior da mulher na sociedade.

É verdade que, a princípio, a contemporaneidade parece oferecer um repertório mais vasto para as mulheres. Também é verdade que as mulheres que passaram a ocupar o mercado de trabalho se tornaram cada vez mais competitivas em 
relação aos homens. A liberação das mulheres incluiu, também, a liberação sexual, com o advento de métodos anticoncepcionais cada vez mais modernos. Isso não é sem conseqüências.

Estas questôes, como sabemos, fazem eco nos consultórios dos psicanalistas. Recebemos mulheres aparentemente emancipadas, bem-sucedidas profissional e economicamente, que muitas vezes são as responsáveis pelo sustento do lar, da família e até do marido. Freqüentemente, elas se queixam do acúmulo de papéis, da culpa gerada pela falta de tempo para cuidar dos filhos e de si mesmas. Elisa é emblemática desta multiplicidade, intitulando-se como: "Centrífuga multiuso".

As mulheres ainda se queixam de que muitas vezes não sabem que papéis devem ocupar: "a minha mãe, a mãe do meu marido eram assim... Eles esperam que eu, como mulher, seja como elas, mas eu não tenho tempo...”. Cabe-nos perguntar: quem espera o quê, de quem? Algumas nos contam que o tempo está passando e que elas não tiveram, devido aos novos compromissos assumidos, de estudo, de trabalho, a oportunidade de constituírem uma família. Quanto a esta queixa, a tecnologia vem em seu auxílio: as mulheres podem engravidar cada vez mais tarde; e engravidar até mesmo sem um parceiro. É a chamada produção independente, com a ajuda dos bancos de sêmen. Aliás, hoje, o culto à maternidade não é mais apenas um privilégio feminino. Estamos falando da possibilidade, atualmente, de adoção de filhos por casais homossexuais, bem como da repercussão que os novos parâmetros dos relacionamentos podem ter, do ponto de vista subjetivo.

Voltando à questão do feminino, cada vez mais abrem-se inúmeras vias. Através dos avanços da tecnologia em relação à maternidade, esta passa a ser uma opção, já que hoje é possível às mulheres escolherem se vão, ou não, se casar, ou ter um companheiro fixo, e se querem, ou não, ter filhos. Estas questōes, por paradoxais que possam parecer, neste cenário contemporâneo, não tratam especificamente da questão da mulher. Ocorre que, de acordo com Freud (1933/1996), um filho representa um substituto fálico diante da angústia de castração, experiência vivida por todas aquelas que puderam percorrer o caminho que conduz para a feminilidade, ou seja, uma posição subjetiva de gozo marcada pelo "não ter" o falo. Assim, ser mãe é buscar uma satisfação no bebê-falo e, portanto, ocupar uma posição disjunta de "A Mulher", aquela que é marcada pela falta. Conjugar estas duas posições - a de mãe (ter) e a de mulher (ser) - não é para todas...

Podemos constatar na modernidade uma ampliação das vias discursivas para que a mulher possa tecer respostas possíveis ao que é da ordem do "seu querer". Mas as respostas possíveis são de ordem fálica, ou seja, relativas ao ter: marido, amante, filho, trabalho, babá, etc. Como encaminhar as respostas concernentes ao ser? 
Kehl (1998) associa o desejo de Ema de tornar-se outra, posteriormente intitulado e catalogado como bovarismo, aos ideais burgueses. Anderson (1999) nos diz que não há na contemporaneidade nenhuma classe comparável à do capitalismo nos moldes do século XIX, ou seja, atualmente não encontramos nenhuma classe emergente que possa ser comparada à burguesia do século XIX. Porém o desejo bovarista de Ema atualiza-se com Elisa em Aritmética.

Parece-nos que o desejo bovarista não é circunstancial ao século XIX. Este desejo, que enunciamos como "desejo de tornar-se outra", está presente em Ema, bem como em Elisa. Vejamos: nossa querida Ema, insuflada pelos ideais burgueses a abandonar a pacata vida do campo para viver o turbulento e apimentado modo de vida dos salões de Paris, buscava assemelhar-se às heroínas dos romances que lia. Já Elisa, que deixou a infância pobre, tornando-se reconhecida e bemsucedida jornalista, nos diz: "Sartre um dia escreveu: tudo é uma questão de recapitulação. [...] Mais uma vez, facilitando a questão: será que uma história revista não passa a ser uma nova história? Como, por exemplo, Sartre descreveria Elisa?” (Young, 2004: 58-59). Uma "nova história", uma outra Elisa, uma Me-lissa, a Elisa de Eduardo. Estamos, então, nos perguntando, uma vez que já sabemos que "A Mulher não existe", quais podem ser as suas possibilidades de contornar o que as define como não-todas fálicas, como podem lidar com este mais além que está fora da linguagem... Vejamos, pois, como Elisa enuncia esta "recapitulação":

Elisa sabia precisamente o homem que tinha ao lado. Ou os homens, incluindo Rigel. E era o tempo que gastava com isso, saber precisamente dos homens, que ela, às vezes, achava sem sentido. Já tinha marido, amante, poesia, sexo. O que ela queria afinal de contas? Ter tudo? Todos? O criador não deveria se sentir satisfeito com sua criação? (Young, 2004: 69-70).

Pois Elisa precisou de um empréstimo à sua narrativa, precisou da Elisa de Eduardo, Me-lissa, antes de poder escrever uma versão de próprio punho. Vejamos: "Elisa está ótima, melhor do que nunca, foi musa. E Rigel? Rigel nem está no livro. [...] Ela foi aquilo que fez: viveu outro, tendo outro, em busca de si mesma” (Young, 2004: 253).

Esta recapitulação de nossas heroínas é o que propomos como hipótese, como um ponto de engate característico da posição feminina em ambas as produçôes discursivas. Resta ainda saber se a produção discursiva contemporânea oferece um terreno mais fértil para que as mulheres possam escrever um nome, ou nomes, que sejam seus, diferindo, assim, de um enlace imaginário que parece ser característico do que descrevemos como bovarismo. 


\section{A IMAGEM}

O tema da imagem já foi apontado por nós como um dos fatores decisivos para que pudéssemos mostrar a urdidura de uma determinada produção discursiva. Gostaríamos, mais uma vez, de apontar os deslocamentos que a questão do público versus privado sofreu desde sua instauração na modernidade até a contemporaneidade, no que nos interessa a respeito do feminino.

De acordo com Nunes Jr. (2005), "A natureza feminina sempre ocupou um papel bem definido no pensamento cristão" (Nunes Jr., 2005: 17). Sendo portadora da maldição, a imagem da mulher foi sempre vista com desconfiança, ou, pior que isso, com temor. $\mathrm{O}$ afastamento da mulher dos perigos do mundo encontra expressão, como vimos, na produção discursiva do século XIX, tal como Rousseau (1782/2004) nos informa sobre "as rainhas do lar".

A literatura do século XIX visava criar, segundo Kehl (1998), "os códigos burgueses, de si e do lar, que compuseram o imaginário feminino sobre o casamento, moldando as expectativas românticas do amor-paixão pelo lado da literatura...” (Kehl, 1998: 108). A mulher, portanto, até o século XIX, podia reinar quase que exclusivamente no âmbito "privado". Contudo, as mudanças no paradigma econômico, o ingresso do capitalismo em sua fase mais abstrata nos fizeram ingressar na era da sociedade do espetáculo e da embalagem. Observamos uma intersecção cada vez mais tangível entre o que diz respeito ao público e ao privado. Esta intersecção é representada principalmente pelos veículos de massa como, por exemplo, o programa exibido em rede nacional, Big Brother, como todos os reality shows, as revistas e programas sobre as intimidades dos "famosos", etc, e também por alguns títulos literários, já que está na moda tornar pública toda a intimidade. Para nós, fica patente que não há mais uma clara fronteira entre o que pode ser definido como público e como privado. Isto, também, não é sem conseqüência no que diz respeito ao campo discursivo e imaginário sobre o feminino.

Mais que pública, a intimidade, assim como a cultura, tornou-se consumível. A este respeito, nos diz Jameson (2004): "na cultura pós-moderna, a própria 'cultura' se tornou um produto, o mercado tornou-se o seu próprio substituto, um produto exatamente igual a qualquer um dos itens que o constituem" (Jameson, 2004: 14).

Como sabemos, dentre os itens constituídos e produzidos pela cultura, também figura a literatura como produto. Cultura, produto, consumo tornam-se itens de uma cadeia que, na contemporaneidade, com o auxílio dos veículos de massa como a televisão e a internet e a própria imprensa, aumentaram significativamen- 
te o acesso à informação, não discriminando o gênero, classe social, nível de instrução, diferentemente da produção literária do século XIX.

De acordo com Ipsos Marplan (2004) ${ }^{1}$, com relação aos hábitos de mídia das mulheres: $52 \%$ da amostra pesquisada lêem revistas habitualmente, 43\% lêem jornais, 98\% assistem televisão diariamente, 37\% lêem revistas femininas.

Aumenta significativamente, na contemporaneidade, a produção de títulos destinados ao público feminino. Dentre estes assuntos, oferece-se "o manual da mulher contemporânea, modo de usar": "como tornar sua vida sexual mais prazerosa", "como dar mais prazer ao seu parceiro", "como se livrar da celulite", "como ser uma profissional bem-sucedida", "como educar seu filho"; manual respaldado pelas dicas de especialistas das mais diversas áreas: pedagogos, psicólogos, médicos, esteticistas, etc.

Diante deste cenário contemporâneo, temos que a literatura e a produção escrita não aparecem nos dados de Marplan, acima mencionados, pois devem ocupar um lugar modesto de acesso, ainda hoje, para boa parte dos brasileiros. Em contrapartida, há um lugar privilegiado da mídia e dos veículos de massa no modo como se perfazem as produções discursivas atuais. Diante deste cenário, fizemos a escolha da obra Aritmética de Fernanda Young (2004), que, além de escritora e romancista, é roteirista de cinema, de programas de televisão, e escreve colunas para jornais e revistas de grande circulação. Desta forma, entendemos que Fernanda Young e sua letra são protagonistas ideais do cenário que acabamos de apresentar.

Destacamos que o afrouxamento, o esfumaçamento entre as fronteiras que estabeleciam o estatuto social, o gênero, a posição social, etc, é uma marca da sociedade contemporânea. Ficam cada vez mais amorfos os papéis sociais, sexuais, assim como a fronteira entre o público e o privado.

A respeito deste último item, Elisa, personagem de Aritmética, oferece-nos um exemplo pitoresco. Enquanto Ema, de Flaubert, "era a apaixonada de todos os romances, heroína de todos os 'dramas', a vaga 'ela' de todos os volumes de versos" (Young, 2004: 200), Elisa, pela letra de Eduardo - romancista e seu amante -, tornara-se Melissa, a protagonista do romance de Eduardo em suas tórridas atuaçôes com o autor. Assim, Elisa encontra Me(elisa), a Elisa de Eduardo, devidamente recapitulada: abriu o livro de Eduardo só para ver como começava, "pois já estava com sono, e quando parou de ler havia terminado: 246 páginas... Maldito ladrão, roubando as suas intimidades para expô-las em público. Oferecendo a vagina dela na prateleira da Literatura Nacional” (Young, 2004: 122).

Modificaram-se substancialmente as formas de relação. As variantes históricas de como se apresenta o amor, em grande parte, constituiu-se como produto da 
arte, da literatura, da religião. O termo "produto" aqui não parece ser um termo casual, já que também o amor na contemporaneidade parece ser não apenas almejável, mas, também, consumível.

Como o amor e o tornar-se desejável também entraram na linha de consumo, relembremos o curioso movimento das mulheres que abandonaram o desconforto dos espartilhos, queimaram sutiãs em praça pública em nome do movimento feminista e, curiosamente, hoje lotam as salas de espera dos cirurgiões plásticos, medindo sua sensualidade em mililitros de silicone.

Seus problemas acabaram! Será? Adquira já o corpo com que sempre sonhou. Não perca tempo! O corpo deixou de ser um desígnio divino, à imagem e semelhança de Deus, para se assemelhar às "deusas" da passarela. Totalmente fashion. Procusto reeditado pela ordem do capital! Corta aqui, estica ali, fure, tatue. Body Art. É a mais-valia da carne.

É a moda ditando os referenciais do desejável. Isto, como sabemos, afeta diretamente as mulheres, uma vez que estas se inscrevem no par sexual por se deixar desejar, ou seja, ocupando um lugar de objeto do desejo do outro, que é lido e moldado em nome da ditadura da estética. A importância da incidência da castração na mulher, a ser escutada como uma operação simbólica que determina uma posição subjetiva de gozo, parece adquirir um estatuto real na modernidade: perder, no mínimo, uns dois quilos, para caber no "modelito" exclusivo prêt-àporter, manequim 38, adquirido na última liquidação por uma "pechincha". Como nos diz Young (2004), após a maternidade: "Primeiro emagreceu, para caber na fantasia de walita ambulante, seu novo papel na sociedade" (Young, 2004: 163). Diríamos nós... para caber na "medida".

O imaginário social se uniformiza de um modo sem precedentes na história. Há um investimento desmedido na aparência do eu, por meio de uma estética ditada culturalmente. [...] Em tal sociedade, dominada pelo culto à imagem, que tem no ideal de sucesso e felicidade, a qualquer custo, seus valores maiores, não existe direito ao sofrimento, à tristeza, à dúvida. Tem-se que ser feliz, custe o que custar! Amordace-se a angústia, seja pagando o preço de uma dependência química (de drogas legais ou ilegais), seja pagando o preço de uma alienação siderada - como na adesão incondicional às seitas e religiôes fundamentalistas - seja pagando o preço de viver um tempo sem tempo - o tempo instantâneo e alucinado dos workaholicks (Santa Cruz, 2002: 41).

Por falar em moda, temos a pretensão de afirmar que hoje ninguém é totalmente fashion sem uma síndrome. Agora, sob os auspícios da ciência, a loucura deve ser diagnosticada, tratada, institucionalizada, medicada, precisamente des- 
crita e reconduzida à condição de normalidade e de normatização. A loucura é revista sob várias perspectivas: como doença e cientifizada, ela desconstitui e declina o sujeito. Por outro lado, como dimensão essencial da cultura, entendida como desrazão, estranheza, ameaça, alteridade radical, ou seja, tudo o que a civilização enxerga como seu limite, seu contrário, seu Outro, coube ao louco encarnar este sujeito fora da sociedade, atrás dos muros das instituições psiquiátricas, expulso da sociedade, à medida que a loucura é cada vez menos subjetiva e mais cientifizada. Perguntamos se uma catalogação nosológica pode encerrar um saber sobre o sujeito a fim de administrá-lo. Por este motivo, evitamos, com Ema e Elisa, possíveis diagnósticos e privilegiamos suas produçôes discursivas.

De outra forma, os diagnósticos, como vimos, têm feito sucesso desde o século XIX. Para todos os males, síndromes e transtornos devidamente diagnosticados e carimbados por um especialista, a indústria farmacêutica oferece a sua tecnologia e um vasto coquetel "medicamentoso". Entretanto, se vemos multiplicarem-se os diagnósticos e a cura química para seus males, o diagnóstico da histeria, que fez tanto eco no século XIX, atualmente parece ter saído de moda. $\mathrm{Na}$ introdução do CID-10 encontramos a seguinte citação: "O termo 'histeria' não foi usado no título de nenhum transtorno no capítulo $\mathrm{V}(\mathrm{F})$ da CID-10, por causa de muitas e variadas gradações de significados" (Organização Mundial de Saúde, 1993: 14-15). Os transtornos, ou seus indícios fenomenológicos que antes eram denominados como histeria, foram reagrupados sob os diagnósticos dos Transtornos Dissociativos, Somatoformes e Transtorno de Personalidade Histriônica. O reordenamento da nosologia psiquiátrica não nos parece casual, uma vez que concordamos com Kehl (1998) quando diz que a mulher no século XIX aparece como um sintoma dos deslocamentos que transformaram a vida social como um todo, encarnado, literalmente, nas paralisias, conversões e etc. Mas ao que se deve o fato de o diagnóstico de histeria, ou neurose histérica, desaparecer da nosologia psiquiátrica atual?

É verdade que hoje não recebemos no consultório, com a mesma freqüência que no século XIX, estas denunciadoras. Ou pelo menos não as recebemos com os mesmos sintomas de antes. Sinal dos tempos. Hoje recebemos, mais freqüentemente, pacientes que já fizeram seu autodiagnóstico, entre os que desfilam nas paradas de sucesso: "Doutora, eu estou deprimida, ou tenho Síndrome do Pânico. Tenho medo de estar ficando bulímica, eu vi na televisão e fiquei preocupada”. A multiplicação dos diagnósticos de depressão parece ser um grande tema contemporâneo. A depressão chegou mesmo a ser intitulada como o "grande mal moderno". Curiosamente, a prevalência dos diagnósticos citados é maior entre as mulheres $^{2}$ e Elisa nos explica: 
As mulheres reclamam, mas sem esta obviedade masculina para acompanhá-las estão fadadas a se perderem pelo caminho. Vindo lotar a sala de espera dos médicos, com os seus milhares de achaques psicossomáticos. Que precisam de um atestado de existência e os médicos fornecem. Pois não há nada mais prático que um diagnóstico. Por isso, as mulheres vivem mais tempo: elas têm remédios para todas as suas lamúrias e alguns deles acabam funcionando. Elisa não quer mais nada disso. Quer ser vanguarda de uma nova geração de mulheres. Que não precisa de homens, ou que não precisará pelos motivos que hoje precisa. $\mathrm{Mu}$ lheres serão menos chatas, menos carentes, menos desesperadas... (Young, 2004: 332-333).

Vamos recorrer, mais uma vez, à literatura e a Young (2004):

Virginia Woolf descreveu a medida certa de sensações e reações que o homem deve ter para não atravessar a linha da lucidez... Estar dentro da medida, escreve Woolf, é estar no limite do senso das pessoas que (aqui já tomo a liberdade de falar por mim) vivem suas vidas sem causar ruídos, mesmo após saborear vários de seus diários drinques [...], elas não perdem a pose. A divina medida freqüenta ambientes decorados por arquitetos. As exposições na Pinacoteca. Deusa sempre com os cabelos bem tingidos e bem escovados. Dizendo coisa com coisa, o verbo preciso (Young, 2004: 100).

Eis a divina Medida, de Virgínia Woolf, de Fernanda Young, e, a partir de Freud, diríamos: "Moral sexual civilizada da contemporaneidade". Nos parágrafos anteriores, tentamos esboçar como esta "divina medida" parece atualizar-se em relação aos parâmetros contemporâneos do capital abstrato e do "mundo da embalagem". Elas podem o que querem?

Quando os versos da gente não podem ser compreendidos, nem o espírito secundado pela questão que se chama entendimento, é coisa pior para deixar como morto, do que uma cota grande em quarto pequeno. Em verdade, desejara que os deuses te houvessem feito com disposição poética (Shakespeare, 1559, citado por Bloom, 2000: 279).

Ao longo do texto, retomamos, a partir de um recorte, a questão enunciada por Freud "Was will das Weib", o que quer a mulher? Isto significou retomála pelo viés lacaniano - o que quer uma mulher ? Não tentamos responder esta questão como uma verdade absoluta. Pelo contrário, tentamos diferenciar o que descrevemos como o conceito de posição subjetiva feminina e o discurso sobre o feminino, este, tecido por fatores históricos e culturais. A partir do que consi- 
deramos três aspectos fundamentais, a saber, o capital, o tempo e a imagem, situados como panos de fundo do cenário discursivo do século XIX e do cenário contemporâneo sobre as mulheres, nós as colocamos em cena. Também tentamos demonstrar como estes três fatores se encaixam como em um caleidoscópio, formando a produção discursiva e imaginária de cada tempo e, por fim, tentamos apontar seus enodamentos, os pontos de ancoragem de uma determinada posição subjetiva em cada cenário. Cabe-nos agora tratar de seus possíveis deslocamentos.

Para tanto, retomaremos o texto freudiano "Moral sexual civilizada" (1908/ 1996). Perguntamos se a produção discursiva contemporânea oferece, de fato, um terreno mais fértil que o do século XIX, para que as mulheres que hoje se desdobram em tantos papéis possam brilhar e escrever um nome, ou nomes, como uma père-version, que seja seu.

É verdade que, a princípio, a contemporaneidade parece oferecer um repertório mais vasto para as mulheres. Acompanhamos o que se costuma chamar de a "liberação feminina”, que causou uma substancial modificação no cenário social e sexual que as mulheres passaram a ocupar. Também é verdade que as mulheres entraram no mercado de trabalho e se tornaram cada vez mais competitivas em relação aos homens; que a liberação das mulheres incluiu também a liberação sexual. Se por um lado se amplia o terreno pelo qual as mulheres podem caminhar, isso não diz respeito ao "feminino" como tal. Perguntamos-nos se o alinhamento cada vez maior das mulheres do lado do gozo fálico não vem justamente a obturar a questão propriamente feminina do não-todo.

Já sabemos que as mulheres foram objetos da ciência, da literatura, das artes em geral, da medicina. Nossa querida Ema, inclusive, contribuiu para que o termo bovarismo fosse incluído na nosologia psiquiátrica. A mulher também foi objeto da filosofia - tal como nos foi apresentada a Sofia de Rousseau (1782/ 2004) -, da religião e da própria psicanálise.

Porém, como objeto, como parceira do desejo masculino, a mulher, as mulheres, ou cada mulher deixa na obscuridade a questão de seu próprio desejo. "Dark continent", como o intitulava Freud. Che vuoi? Que queres? Mas o que é da ordem do desejo, da palavra, se situa do lado do falo. Como já dissemos, Lacan situa a posição feminina do lado do não-todo. Então, a respeito do gozo, que diz respeito propriamente ao feminino, que podemos dizer? Lacan (1972-73/1985) comenta: "O que dá alguma chance ao avanço, isto é, que desse gozo a mulher nada sabe, é que há tempos lhe suplicamos de joelhos - eu falava da última vez das analistas mulheres - que tentem nos dizer, pois bem, nenhuma palavra!... Então a gente chama como pode" (Lacan, [1972-73] 1985: 101). 
Para apontar alguma perspectiva para as mulheres, nova em relação ao século XIX, relevante e capaz de produzir efeito, tomamos uma citação de Ligya Fagundes Telles (2000): "Antes a mulher era explicada pelos homens... [...] Agora é a própria mulher que se desembrulha, se explica" (Telles, 2000: 761).

Esta possibilidade, que Freud inaugurou ao escutar o que a(s) mulher(es) de sua época tinham a dizer, abre caminho para que as mulheres, fora da "proteção" do lar, figurando no campo profissional, nas universidades, na literatura, sobre o divã, ou onde mais possam se fazer escutar, se expliquem. Que possam construir versões daquilo que não podem falar, daquilo que não sabem dizer.

Dizemos versões, pois que a verdade, como a mulher, é também não-toda... Há ainda muito a dizer. Pois que elas possam falar!

\section{REFERÊNCIAS BIBLIOGRÁFICAS}

American Psychiatric Association. (1994). Diagnostic and Statistical Manual of Mental Disorders: DSM-IV. Washington: APA.

André, S. (1998). O que quer uma mulher? Rio de Janeiro: Jorge Zahar.

Anderson, P. (1999). As origens da pós-modernidade. Rio de Janeiro: Jorge Zahar.

Bloom, H. (2000). Shakespeare: a invenção do humano. Rio de Janeiro: Objetiva.

Coelho, N. C. (1989). Tendências atuais da literatura feminina no Brasil. Em Coelho, N.

N. Feminino singular (pp. 4-13). São Paulo: GRD.

Flaubert, G. (1856). Madame Bovary. São Paulo: Abril Cultural, 1971.

Freud. S. (1908). Moral sexual civilizada e a doença nervosa. Obras completas, ESB, v. IX.

Rio de Janeiro: Imago, 1996.

. (1933). Feminilidade - Novas conferências introdutórias sobre psicanálise -

Conferência XXXIII. Obras completas, ESB, v. XXII. Rio de Janeiro: Imago, 1996.

Grant, W. H. (1998). A mascarada e a feminilidade. Psicologia USP, 9, 2, 249-260.

Ipsos Marplan. (2004). Estudo Marplan.

Jameson, F. (2004). Pós-modernismo: a lógica cultural do capitalismo tardio. São Paulo: Ática.

Jones, E. (1989). A vida e obra de Sigmund Freud. Rio de Janeiro: Imago.

Kehl, M. R. (1998). Deslocamentos do feminino: a mulher freudiana na passagem para a modernidade. Rio de Janeiro: Imago.

Lacan, J. (1953). Função e campo da fala e da linguagem em psicanálise. Em Escritos (pp. 238-324). Rio de Janeiro: Jorge Zahar, 1998.

(1972-73). O seminário, livro XX, Mais, ainda. Rio de Janeiro: Jorge Zahar, 1985. 
Nunes Jr., A. B. (2005). Exxtase e clausura: sujeito místico, psicanálise e estética. São Paulo: Annablume.

Organização Mundial de Saúde. (1993). CID-10 - Classificação de doenças mentais e de comportamento: descriçôes, clínicas, e diretrizes diagnósticas. Porto Alegre: Artes Médicas.

Pelbart, P. P. (1993). A nau do tempo-rei: sete ensaios sobre o tempo da loucura. Rio de Janeiro: Imago.

Rodrigué, E. (1995). Sigmund Freud. O século da psicanálise, v.1. São Paulo: Escuta.

Rousseau, J.-J. (1782). Emílio, ou da educação. São Paulo: Martins Fontes, 2004.

Santa Cruz, M. A. (2002). O paradoxo da saída feminina na cultura contemporânea. Em Alonso, S. L.; Gurfingel, A. C.; Breyton, D. M. (Orgs.). Figuras clínicas do feminino no mal-estar contemporâneo (pp. 33-44). São Paulo: Escuta.

Telles, L. F. (2000). Mulheres, mulheres. Em del Priore, M. (Org.). Historia das mulheres no Brasil (pp. 669-672). São Paulo: Contexto.

Young, F. (2004). Aritmética. Rio de Janeiro: Ediouro.

\section{Notas}

1 Pesquisa de mercado realizada pelo Instituto Ipsos sobre o perfil da mulher brasileira em 2004, com uma amostra de 27470 mulheres, para os veículos de comunicação.

2 Ver American Psychiatric Association, DSM-IV (1994), páginas 325; 399 e 548.

Recebido em 19 de junho de 2007 Aceito para publicação em 16 de novembro de 2007 